\title{
DESIGN AND ANALySIS OF RECTANGULAR SLOT Microstrip PATCH ANTENNA For MILlimetre- WAVE COMMUNICATION AND ITS SAR EVALUATION
}

\author{
B.V.Naik ${ }^{1,2}$, Debojyoti Nath ${ }^{3}$, Rina Sharma ${ }^{1,2}$ \\ ${ }^{1}$ CSIR-National Physical Laboratory, Dr KS Krishnan Marg, New Delhi-110012, India \\ ${ }^{2}$ Academy of Innovative and Scientific Research (AcSIR), Ghaziabad-201002, India \\ ${ }^{3}$ Department of Electronic Sciences, University of Delhi, South \\ Campus, New Delhi, India
}

\begin{abstract}
This paper presents the design and analysis of the compact patch antenna for $5 G$ and future generation millimetre-wave communication system. The proposed design consists of FR4 substrate length, width, and height of $21.37 \times 5 \times 1.59 \mathrm{~mm}^{3}$, besides two rectangular slots incorporated with a dimension of $0.2 \times 2.6$ $\mathrm{mm}^{2}$ within the patch of $4.22 \times 3.46 \mathrm{~mm}^{2}$, to enhance the resonance frequency more accurate and one more square slot incorporated in to feed line with the dimension of $0.2 \times 0.5 \mathrm{~mm}^{2}$. The obtained return losses of the design is $-21.25 \mathrm{~dB}$ with gain and voltage standing wave ratio (VSWR) of 3.90dBi,1.18 by using a lumped port configuration. For the specific absorption rate (SAR) evaluation considered as a human head model in high-frequency structure simulator (HFSS) software, the obtained values are within the standard limit, the design covers the frequency range of $28 \mathrm{GHz}$, this design may capable of $5 \mathrm{G}$ and next-generation wireless communication system application.
\end{abstract}

\section{KEYWORDS}

Patch antenna, SAR, Rectangular slot, Human head model

\section{INTRODUCTION}

There are tremendous changes has been observed in mobile communication since last few decades, the mobile devices and connections are not only getting smarter in their computing capabilities but also evaluating lower generation network connectivity technologies i.e. $1 \mathrm{G}, 2 \mathrm{G}$ to higher generation technology (3G, 3.5G, and 4G or LTE) [1,2]. The first generation technology pertained to voice transmission services only were highly incompatible with related services it was introduced in the early 1980s[2], the second-generation wireless cellular mobile technology was planned for voice transmission with digital data transfer and the data transfer rate up to 64 kbps. This technology ahead of $1 \mathrm{G}$ services by providing the facilitate short message services (SMS) and lower speed data such as CDMA2000, the second generation technology deploying GSM services, Global system for mobile communication uses digital modulation schemes to improve the voice quality but network offers limited data services and the second generation carriers continued to improve the transmission quality and coverage, also, it began to offer text message services, voicemail, and fax service.

In the 2.5 generation technology introduced General packet radio services (GPRS)[1-3], it 
implies packet-switched data capabilities to existing GSM services and also it allows to user can send graphical data as packets, the importance of the packet switching increased with rising of internet and internet protocol (IP),3rd generation technology based on wideband wireless evolution intends to mobile telephone customer to use audio, graphics, and video application data transfer rate up to $200 \mathrm{kbps}$. This technology enhances the clarity and speed of the network up to megabits per second, for the Smartphone and mobile modems in laptop computers. Fourthgeneration technology brought in Long Term Evaluation (LTE), this technology comes under 3GPP (Third Generation Partnership Project) Standard it fulfils (International Telecommunication Unit) ITU, (International Mobile Telecommunication) IMT -Advanced broadband network, the data transfer rate of the technology up to $1 \mathrm{Gbps}$ and the $4 \mathrm{G}$ provides better than TV quality images, video-links. Furthermore, to enhance the data speed, it is predicted that the commercial deployment of fifth-generation $(5 \mathrm{G})$ systems will be approximately in the early 2020s [4]. To meet the increasing need for even higher data rates required in future applications (such as wireless broadband connections, massive machine-type communications, and highly reliable networks), the research activities on $5 \mathrm{G}$ mobile communication systems have started $[5,6]$. The microstrip antenna has several advantages compared to conventional microwave antennas some of them are lightweight, low volume and thin profile configurations, which can be made conformal, low fabrication cost, readily amenable to mass production, linear and circular polarizations are possible with simple feed, dual-frequency and dual-polarization antennas can be easily made, no cavity back is required, can be easily integrated with microwave integrated circuits [7].

In the existing present wireless communication world antennas are needed to assure some security of the human body from the electromagnetic radiation for that some of the protecting and guiding organization federal communication commission (FCC), European international electro technical commission (IEC) and IEEE 1528 has set the safety limit of $1.6 \mathrm{~W} / \mathrm{kg}$ absorbed by 1gram tissue and $2 \mathrm{~W} / \mathrm{kg}$ for 10 -gram of tissue.

\section{Design and Analysis of the Patch Antenna}

Geometry consists of FR-4 epoxy substrate dimensions of width, length and height are $5 \mathrm{x}$ $21.37 \mathrm{~mm}^{2} \times 1.59 \mathrm{~mm}$ with an epsilon value and the loss tangent of 4.4, 0.017. The design Fed by a microstrip transmission line, and the ground plane made of conducting material i.e., copper. The patch consists width and length of $4.22 \times 3.46$ with two rectangular slots dimensions of $0.2 \times$ $2.6 \mathrm{~mm}^{2}$, to enhance resonance one more square $0.2 \times 0.5 \mathrm{~mm}^{2}$ dimension feed slot incorporated to the patch. The considerable height of the patch is smaller than the wavelength of operation, the proposed design resonate frequency is $28 \mathrm{GHz}$, as per design the detailed dimensions are given in Table 1 with respective the Fig. 1

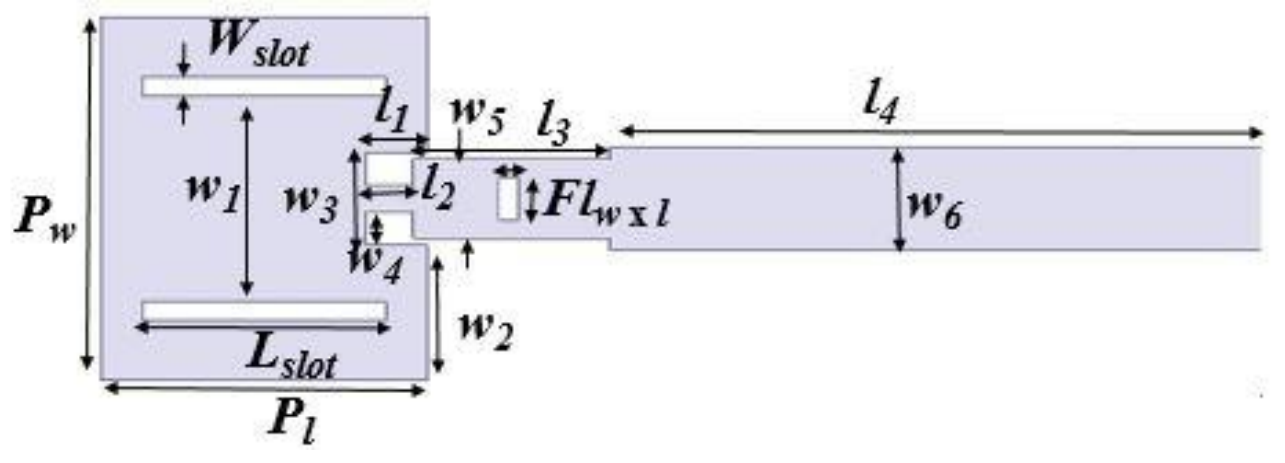

Figure 1: The geometry of the Rectangular Slot patch antenna 
Table 1. Dimensions of the Rectangular slot Microstrip patch antenna

\begin{tabular}{|c|c|}
\hline Parameters & $\begin{array}{c}\text { Dimensions } \\
\text { in }(\mathbf{m m})\end{array}$ \\
\hline Substrate Width & 5 \\
\hline Substrate Length & 21.37 \\
\hline Height of Substrate $\left(\mathrm{h}_{\mathrm{t}}\right)$ & 1.59 \\
\hline Patch Length $\left(P_{l}\right)$ & 3.46 \\
\hline Patch Width $\left(P_{W}\right)$ & 4.22 \\
\hline Slot Width $\left(W_{\text {slot }}\right)$ & 0.2 \\
\hline Slot Length $\left(L_{\text {slot }}\right)$ & 2.6 \\
\hline Between Slot Distance $\left(w_{l}\right)$ & 2.4 \\
\hline Fedd line $\left(F_{w x}\right)$ & $0.2,0.5$ \\
\hline$w_{2,} w_{3}$ & $1.58,1.05$ \\
\hline$w_{4}, w_{5}$ & $0.37,0.91$ \\
\hline$w_{6}$ & 1.19 \\
\hline$l_{1,} l_{2,}$ & $0.65,0.50$ \\
\hline$l_{3,} l_{4}$ & $2.1,8.37$ \\
\hline
\end{tabular}

\section{Measurement Analysis of the Patch Antenna}

To verify the design approaches, the proposed antenna fabricated and measured. The proposed microstrip patch antenna is designed in Ansys High-Frequency Structure Simulator (HFSS). The return losses and voltage standing wave ratio are measured in VNA as shown in Fig. 2 and Near field and the far-field radiation pattern is reported in Fig. 4, as shown in Fig. 2 the simulated and measured return loss plot which shows that resonance frequency of $28 \mathrm{GHz}(7 \%)$ [8], which is in good agreement with the simulated results having a resonance at $28 \mathrm{GHz}(6.7 \%)$. The little versions in simulated and measured results are due to the manufacturing allowance and binding of SMA connector using a conductive adhesive, return loss for covering 5G millimetre wave applications [9-28] is higher than $-10 \mathrm{~dB}$. The proposed design antenna return loss is $-22.21 \mathrm{~dB}$, as shown Fig.2, as well as section A and B, describes the effect of incorporated slots and the parametric analysis slot width, length variation with respective slot as shown Fig.3a,b.

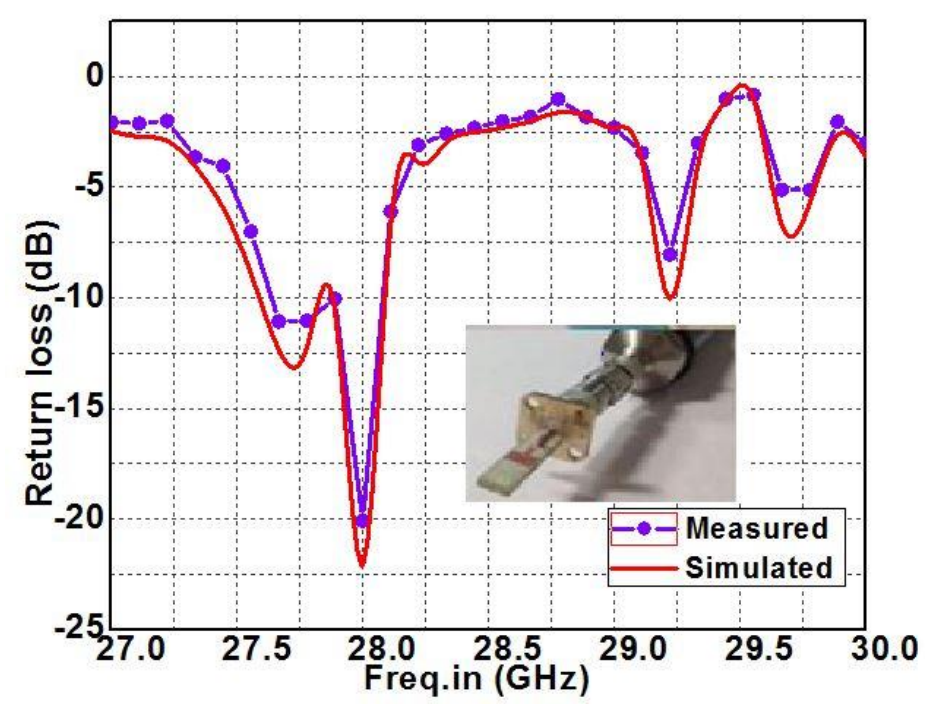

Figure 2: Return Loss of proposed antenna at $28 \mathrm{GHz}$ 


\section{A. Effect of Incorporated Slot}

Incorporating the additional slots to patch the antenna behaviour has been changing i.e. enhancing the return loss and impedance matching, when there were no additional slots present on rectangle patch the antenna shows a non-resonance behaviour at the desired frequency, with increasing the additional slots on the rectangular patch to enhances the matching condition of the antenna, the patch resonating at $23 \mathrm{GHz}$ to $25 \mathrm{GHz}$ to bring the response at the desired frequency at $28 \mathrm{GHz}$.Further, one more slot incorporated on the rectangular patch. the slot width and length variations with respect resonance as given in section $\mathrm{B}$

\section{B. Parametric Analysis}

Parametric analysis is one of the important analysis to determine the optimized results at desired resonance, the proposed antenna slot width variation from $\mathrm{W}_{\text {slot }}=0.02 \mathrm{~mm}$ to $0.2 \mathrm{~mm}$, slot length variation is $L_{\text {slot }}=1 \mathrm{~mm}$ to $2.6 \mathrm{~mm}$ from this observation resonance varies with respective return loss it is reported in Fig.3a, b.

As shown in Fig. 3a describes the variation of slots width with constant length of $2.6 \mathrm{~mm}$ when increasing slot width values from $0.02 \mathrm{~mm}$ to $0.2 \mathrm{~mm}$ the resonance frequency shifts towards the desired response whenever increasing the further value of $0.2 \mathrm{~mm}$ we acquired resonance at 28 $\mathrm{GHz}$, as well as in the Fig. $3 \mathrm{~b}$ demonstrates the slot width keeping constant at $0.2 \mathrm{~mm}$, meanwhile slot length varies at $1 \mathrm{~mm}$ to $2.6 \mathrm{~mm}$, from the $1 \mathrm{~mm}$ to $2.2 \mathrm{~mm}$ the resonance range from 27 to 30 $\mathrm{GHz}$ unmatching condition hence there is no desired response so that whenever increasing the further value of $2.6 \mathrm{~mm}$ the resonance response and impedance matching was enhanced at 28 $\mathrm{GHz}$.

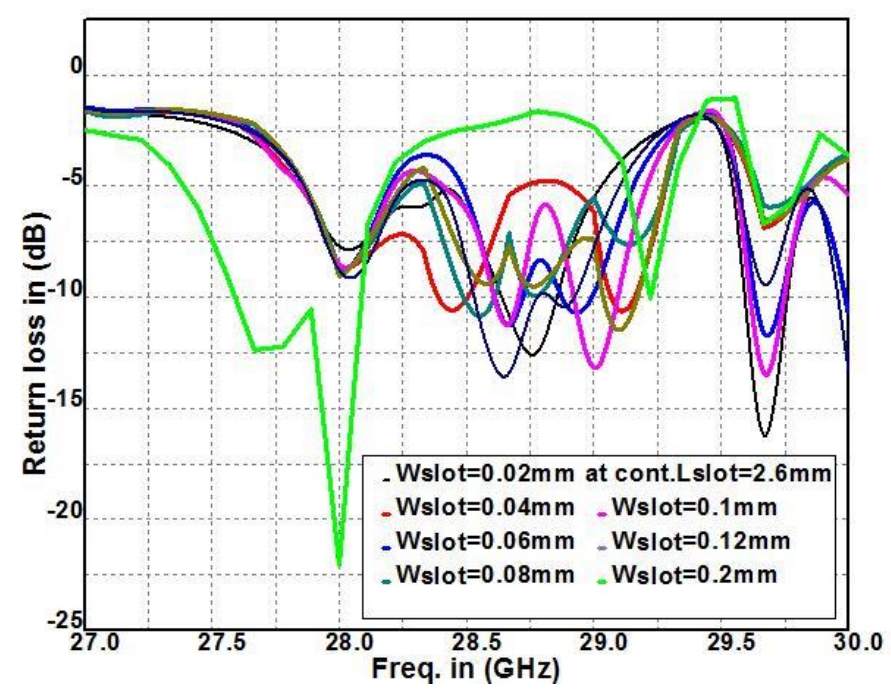

Figure 3(a) : slot width varies with constant slot length 


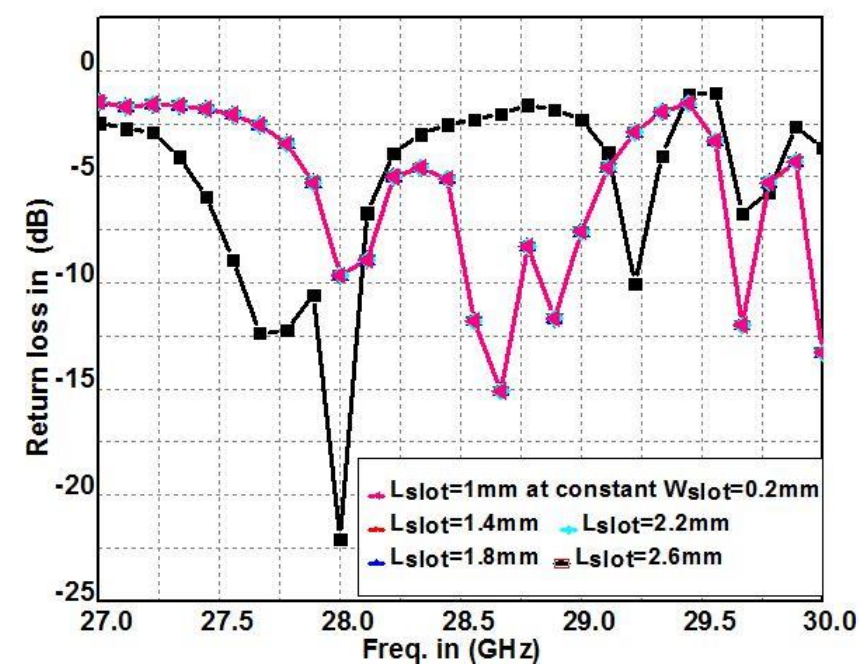

Figure 3(b): slot length varies with a constant slot width

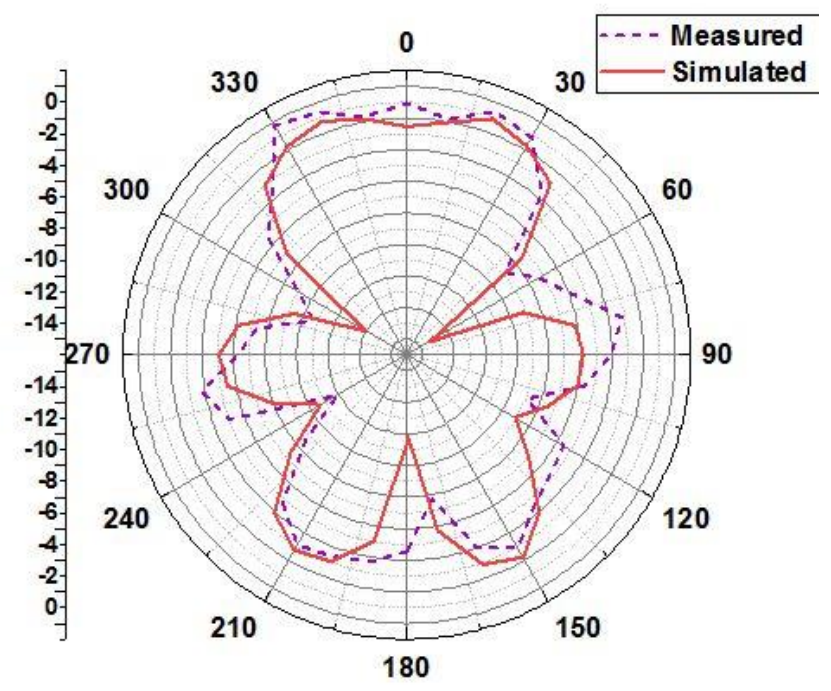

Figure 4(a): Measured and Simulated Radiation pattern

From the above plot, it describes antenna gain versus angle of phi in spherical coordinate from 0 to 360 , this values on the perimeter of the circle while the values inside the circle such as $-14 \mathrm{~dB}$ to $0 \mathrm{~dB}$ are radiation intensity values (gain), so we can observe that at $\mathrm{phi}=0$ degrees simulated gain is approx. $3.9 \mathrm{dBi}$ and the measured value is approx. $3 \mathrm{dBi}$, both values should be quite similar at $28 \mathrm{GHz}$ frequency. 


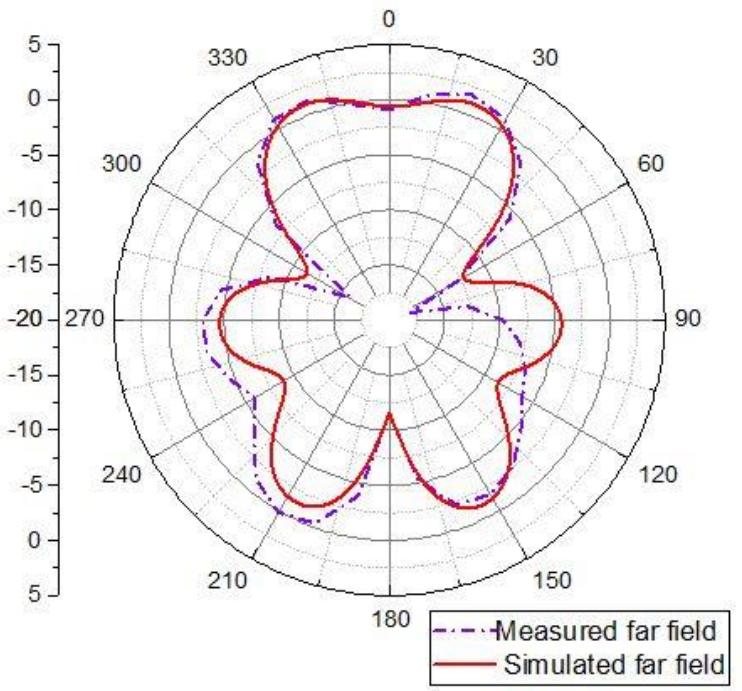

Figure 4(b): Measured and Simulated far-field Radiation pattern

As shown figure $4 \mathrm{~b}$ demonstrate that the values on the perimeter of the circle are angle values from 0 to 360 degree for phi, while the values inside the circle such as $-20 \mathrm{~dB},-15 \mathrm{~dB},-10 \mathrm{~dB},-$ $5 \mathrm{~dB}, 0 \mathrm{~dB}$, and $5 \mathrm{~dB}$ are the radiation intensity values (gain), the measured value is approx. $3.5 \mathrm{dBi}$ and simulated value approx. $3.9 \mathrm{dBi}$ at $\mathrm{phi}=0$ degree, the high gain compact microstrip patch antenna reported in [29], both values are rather similar at $28 \mathrm{GHz}$ resonance, but phi at 75 , degree radiation intensity of simulated value is $-20 \mathrm{~dB}$ and the measured value is approx. $-17.5 \mathrm{~dB}$ at phi 60 degree, same way phi at 300 degrees simulated value is $-20 \mathrm{~dB}$ and the measured value is approx. $-16.5 \mathrm{~dB}$, from this observation the both, are not identical but quite similar

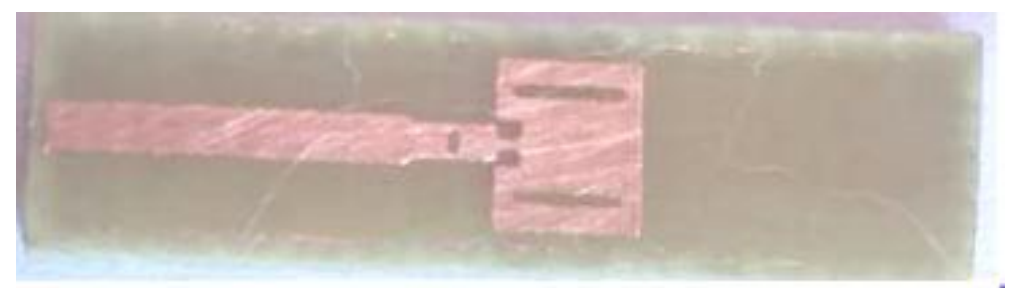

Figure 5: A fabricated prototype of the proposed antenna

$\mathrm{RX}$

R\&S FSV40 Signal and Spectrum analyzer

TX

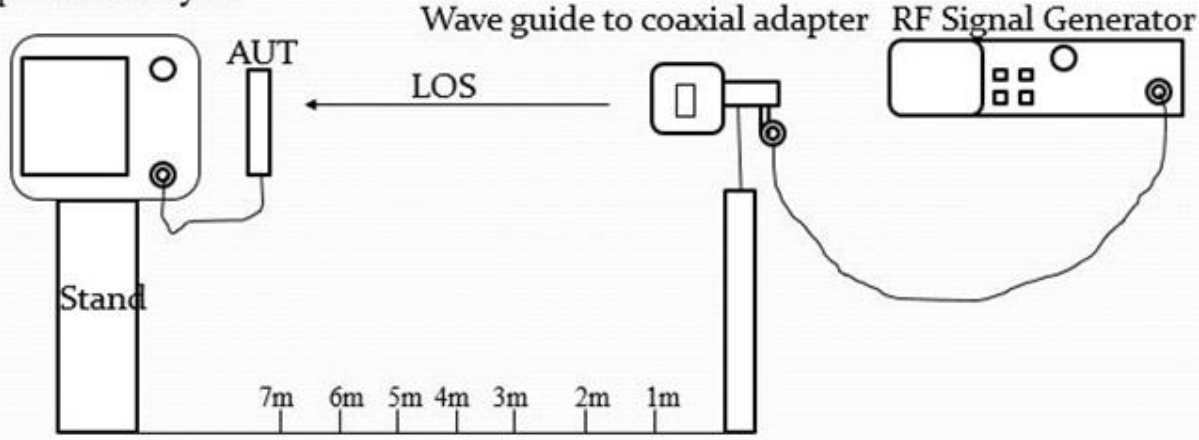

Figure 6: a prototype of the radiation pattern measurement setup 
From the above figure, 6 reports measurement prototype of the radiation pattern, from the RF signal generator selected frequency of $28 \mathrm{GHz}$ with $0 \mathrm{~dB}$ power and it fed up to waveguide adapter, it acts as a transmitter and the second end connected microstrip antenna to the $40 \mathrm{GHz}$ R\&S FSV40 signal and spectrum analyzer. In the antenna under test waveguide to coaxial adapter keeping constant microstrip antenna position changing with respective distance and phi, theta 0 to 360-degree rotation from 1 meter to 7 -meter range. This experiment was done in an indoor environment with a noise level below $-70 \mathrm{dBm}$ (direct antenna gain method)

\section{Specific Absorption Rate (SAR) Analysis}

SAR is the unit of measurement for the RF energy absorbed by any biological tissue (human body) when we use wireless devices, SAR values are measured in W/kg. In this analysis, human head modal has been stimulated in HFSS software at the $28 \mathrm{GHz}$, fed by monopole antenna with proposed design [24] as per IEEE 1528

$$
S A R=\frac{\sigma E^{2}}{M}
$$

Where $\sigma$ is the conductivity of the tissue, $\mathrm{E}$ is the electric field, $\mathrm{M}$ is the mass density of the tissue

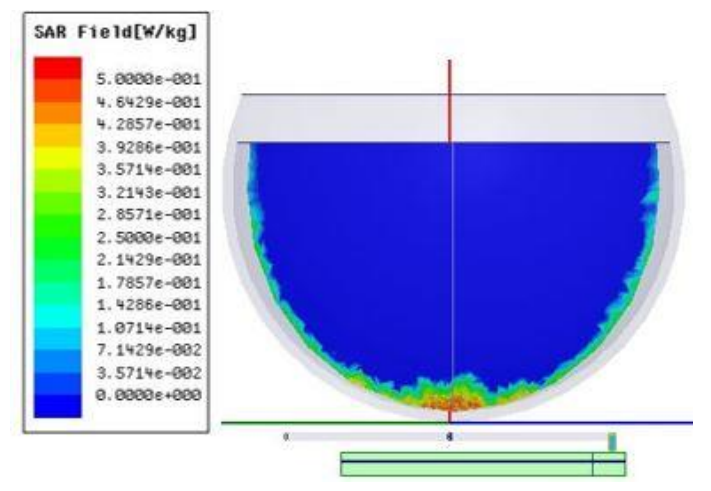

Figure 7(a): Simulated SAR of the proposed antenna with 1 gram biological tissue

As per IEEE/ANSI C63.19 standard, SAR safer limit value should be $1.6 \mathrm{~W} / \mathrm{kg}$ for any $1 \mathrm{~g}$ biological tissue, in the above figure describes SAR value with the limited about $0.5<1.6 \mathrm{~W} / \mathrm{kg}$

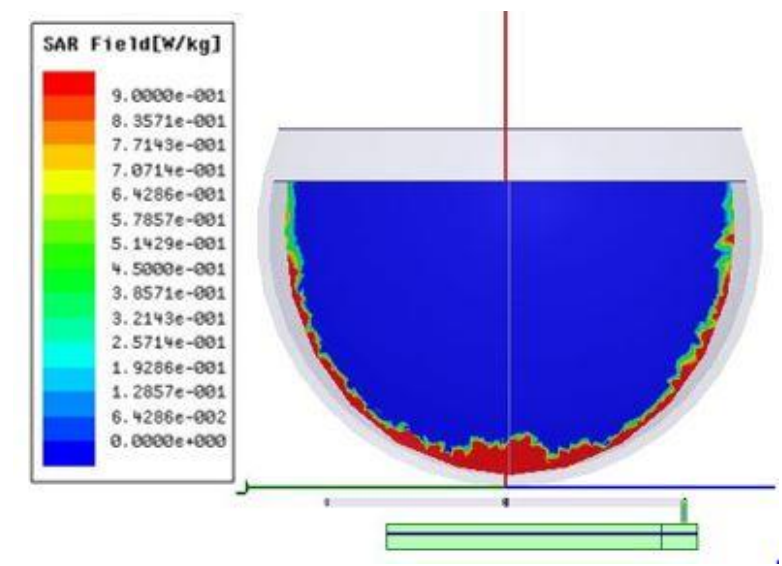

Figure 7(b): Simulated SAR of the proposed antenna with 10-gram biological tissue 
As per the IEEE 1528 standard safer limit of SAR is $2 \mathrm{~W} / \mathrm{kg}$ for any $10 \mathrm{~g}$ biological tissue, in the above figure demonstrates that the max value of $S A R$ is within the limit of $0.9<2 \mathrm{~W} / \mathrm{kg}$.

\section{Conclusion}

This paper portrays the rectangular slot microstrip patch antenna design and analysis has been investigated, various parameters in the design of the antenna are optimized and optimum design is reported. The proposed antenna return loss is $-21.25 \mathrm{~dB}$ The VSWR of the antenna is 1.18 with $7 \%$ bandwidth. The intended antenna structure delineated a gain of $3.90 \mathrm{dBi}$ and SAR investigated results for $1 \mathrm{~g}, 10 \mathrm{~g}$ biological tissue limits are within standard range so, this antenna may find its suitability in future $5 \mathrm{G}-6 \mathrm{G}$ millimetre wave application.

\section{ACKNOWLEDGEMENT}

Authors would like to thank Dr S. K. Dubey for the lab facility, Dr D. K. Aswal, Director CSIRNational Physical Laboratory, for their constant motivation and support throughout this work, and CSIR-HRDG.

\section{REFERENCES}

[1] I J Bahl and P. Bhartia, Microstrip Antenna, Artech House Dedham, MA(USA) 1980.

[2] Shukla, Sapna, et al. "Comparative Study of 1G, 2G, 3G, and 4G." J. Eng. Comput. Appl. Sci, vol.4,pp.55-63,2003.

[3] Pereira V, Sousa T. Evolution of Mobile Communications: from $1 \mathrm{G}$ to 4G. Department of Informatics Engineering of the University of Coimbra, Portugal, vol.4, pp. 20-0,2004.

[4] T.S. Rappaport, et al., "Millimeter-wave mobile communications for 5G cellular: It will work!" IEEE Access, vol.5 pp. 335-349, 2013.

[5] Amit Kumar, Dr YunfeiLiu, Dr Jyotsna Sengupta, Divya, "Evolution of Mobile Wireless Communication Networks1G to 4G”, International Journal of Electronics \& Communication Technology, IJECT, vol.12, pp.68-72,2010.

[6] J. G. Andrews, S.Buzzi, W. Choi, S. V. Hanly, A.Lozano A. C. K., Soong, and J. C. Zhang, "What will 5G be?" IEEE J. Sel. Area of Communication, vol.6, pp. 1065-1082,2011.

[7] Rappaport TS, Gutierrez F, Ben-Dor E, Murdock JN, Qiao Y, Tamir JI. Broadband millimetre-wave propagation measurements and models using adaptive-beam antennas for outdoor urban cellular communications. IEEE transactions on antennas and propagation, vol.4 2013, pp.1850-9,2013.

[8] S. Raja Gopal, Sh. Abu-Surra, Zh. Pi and F. Khan, "Antenna array design for multiGbpsmmWavemobile broadband communication”, Proc. IEEE GLOBECOM'2011, Houston, Texas, pp.1-6, 2011.

[9] R. Garg, P. Bhartia, I. Bahl, A.Ittipiboon, Microstrip antenna design Handbook, Boston: Artech House, 2001.

[10] Desai A, Upadhyaya T, Patel R. Compact wideband transparent antenna for $5 \mathrm{G}$ communication systems. Microwave and Optical Technology Letters, vol.3, pp.781-6,2019.

[11] Tighezza M, Rahim SKA, Islam MT. Flexible wideband antenna for 5G applications. Microwave Opt Technology Lett. , pp.38-44, 2011.

[12] El Mubarak Elobaid HA, Abdul Rahim SK, Hamdi M, Castel X AbedianKasgari M. A transparent and flexible polymer-fabric tissue UWB antenna for future wireless networks. IEEE Antennas Wireless Propagation Lett. ,pp. 1333-1336,2017

[13] Xie W, Wu Y, Wang J, Cui L, Liu Y. A semicircular metamaterial-loaded monopole filtering antenna with high selectivity and harmonics suppression.2017 International Applied Computational Electromagnetics Society Symposium (ACES), pp. 1-2,2017

[14] Dahri MH, Kamarudin MR, Jamaluddin MH, Inam M, Selvaraju R. Broadband Resonant Elements for 5G Reflectarray Antenna Design. Telkomnika, vol. 6, pp. 793,2017. 
[15] Munger D, Duraikannan S. Microstrip Patch Antenna at $28 \mathrm{GHz}$ for 5G Applications. Journal of Science Technology Engineering and Management-Advanced Research \& Innovation., vol.1, pp.2022,2018.

[16] El_Mashade MB, Hegazy EA. Design and Analysis of 28GHz Rectangular Microstrip Patch Array Antenna.WSEASTransactions on Communications, pp.1-9,2018.

[17] Darboe O, Konditi DB, Manene F. A $28 \mathrm{GHz}$ Rectangular Microstrip Patch Antenna for 5G Applications, pp.854-857,2019.

[18] Hong, Wonbin, KwanghunBaek, Youngju Lee, and Yoon Geon Kim. "Design and analysis of a lowprofile $28 \mathrm{GHz}$ beam-steering antenna solution for future 5G cellular applications." In 2014 IEEE MTT-S International Microwave Symposium (IMS2014), vol. 6, pp.1-4,2014.

[19] Ojaroudiparchin, Naser, Ming Shen, and Gert Frolund Pedersen. "A 28 GHz FR-4 compatible phased array antenna for 5G mobile phone applications." 2015 International symposium on Antennas and propagation (ISAP), vol.11, pp.1-4,2015.

[20] Hong W, Baek KH, Goudelev A. Multilayer antenna package for IEEE 802.11 ad employing ultralow-cost FR4. IEEE Transactions on Antennas and Propagation, vol.8, pp.5932-8,2012.

[21] Parment F, Ghiotto A, Vuong TP, Duchamp JM, Wu K. Air-filled substrate integrated waveguide for low-loss and high power-handling millimetre-wave substrate integrated circuits. IEEE Transactions on Microwave Theory and Techniques, vol.3, pp.1228-38,2015

[22] Hong W, Baek KH, Ko S. Millimeter-wave 5G antennas for smartphones: Overview and experimental demonstration. IEEE Transactions on Antennas and Propagation. Vol.8,pp.625061,2017.

[23] Parchin, NaserOjaroudi, et al. "Orthogonally dual-polarised MIMO antenna array with pattern diversity for use in 5G smartphones." IET Microwaves, Antennas \& Propagation 2020.

[24] Lak, A. and Oraizi, H., 2013. Evaluation of SAR distribution in six-layer human head model. International Journal of Antennas and Propagation, 2013.

[25] Rashad NM, Khalaf AA. Modified Design and Fabrication of a broadband Millimeter-Wave AnkhKey Antenna for 5G and Next Generations Applications. In2020 International Conference on Innovative Trends in Communication and Computer Engineering (ITCE), IEEE ., pp. 322-325,2020

[26] Zhang S, Chen X, Kishk AA, Ying Z, Kühn S. Guest Editorial: Special Cluster on 5G/6G Enabling Antenna Systems and Associated Testing Technologies. IEEE Antennas and Wireless Propagation Letters., vol. 19(11), pp.1916-9,2020

[27] Duan BY. Evolution and innovation of antenna systems for beyond 5G and 6G.,2020.

[28] Belot D, González Jiménez JL, Mercier E, Dore JB. Spectrum Above $90 \mathrm{GHz}$ for Wireless Connectivity: Opportunities and Challenges for 6G. Microwave Journal., vol.63(9), 2020.

[29] AlyAboul-Dahab, Mohamed, Hussein Hamed Mahmoud Ghouz, and Ahmed ZakariamAhmed Zaki. "High gain compact microstrip patch antenna for X-band applications." International Journal of Antennas (JANT) Vol 2,2016.

\section{AUTHORS}

Mr Bhukya Venkanna Naik received his B.Tech.(Electronics and Communication Engineering) from the Jawaharlal Nehru Technological University, Hyderabad. He worked as a Hardware Design Engineer in Electronics Corporation of India Limited Hyderabad. Currently, he is member of IEEE MTT-S, Antenna and Propagation Society Member since 2017, and working toward the PhD degree in RF and Microwave Engineering at the Academy of Scientific and Innovative Research (AcSIR), CSIRNPL, New Delhi, India

Dr Rina Sharma received M.Sc. in physics from DAV College Muzaffarnagar, Meerut University in 1983. she obtained M.Tech, PhD in Solid-State Physics from IIT Delhi. Currently, She is Sr. Principal Scientist and Head HRD, Co-Ordinator of AcSIR at CSIR National Physical Laboratory, New Delhi, India.

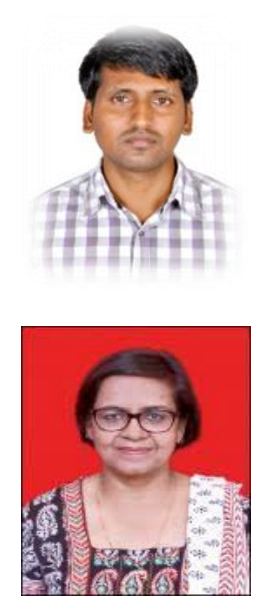

